\title{
Haemophilus Measurement
}

National Cancer Institute

\section{Source}

National Cancer Institute. Haemophilus Measurement. NCI Thesaurus. Code C147458.

The determination of the amount of the organism assigned to the Haemophilus genus in a biological sample. 